\title{
Wear of Fluorapatite Single Crystals: I. A Method for Quantitative Evaluation of Wear
}

\author{
J. M. POWERS and R. G. CRAIG
}

School of Dentistry, University of Michigan, Ann Arbor, Michigan 48104, USA

\begin{abstract}
A quantitative method for characterizing the surface failure of nonmetallic single crystals under sliding was evaluated. It was found that strain rate, load, and slider design influenced the wear of natural fluorapatite single crystals. High loads and slider designs with small radiuses and sharp angles resulted in the deepest penetration.
\end{abstract}

The effect of dentifrices and toothbrushing on the wear of enamel, exposed dentin, and cementum has been the topic of extensive experimental research. ${ }^{1-3}$ Little attempt has been made, however, to study the mechanisms that control the surface failure of enamel under an applied stress that results primarily from sliding. To identify the wear phenomenon of enamel at the level of slip or cleavage interactions or both requires a simplified system that is not influenced by variable or undetermined effects (for example, dentifrice composition and the rate of brushing).

Single crystals have been used in industry for the past decade to study the phenomenon of wear. ${ }^{4-6}$ Bowden, Brookes and Hanwell ${ }^{7,8}$ studied the plowing friction and surface damage of diamond and $\mathrm{MgO}$ single crystals. By sliding conical diamonds with various apical angles on known crystallographic surfaces in specified directions, they related frictional anisotropy and surface damage to specific slip and cleavage interactions.

The purpose of this study was to evaluate a method for characterizing the surface failure of nonmetallic single crystals under sliding, by an investigation of the wear of nat-

\footnotetext{
This investigation was supported by USPHS Training Grant DE-00181 and Research Grant DE-02415 from the National Institute of Dental Research, National Institutes of Health, Bethesda, Md.

This paper was presented in part at the 49th general session of the IADR in Chicago, Illinois, March 1971.

Received for publication March 15, 1971.
}

ural fluorapatite $(F)$ single crystals. This paper describes an experimental procedure and examines the variables of track width, track depth, and area as quantitative measures of wear.

\section{Materials and Methods}

The method of producing wear scars was based on the experiments reported by Bowden, Brookes, and Hanwell. ${ }^{7,8}$ In the present study, diamond sliders of known geometry were slid across the basal surfaces of natural $F$ single crystals in a dry environment. Because only gross effects were sought initially, the effect of crystallographic direction on failure properties was not evaluated. Measurements were based on a series of three one-traversal passes on each of two crystals for a given condition.

Three dependent variables (track width, track depth, and area) were evaluated with respect to four factors (specimen, slider speed, load, and slider design) by means of a factorial design with replications. Analysis of variance ${ }^{9}$ and multiple comparisons ${ }^{10}$ were used to estimate the effects of factors and their interactions. Factors examined in this experimental design are given in $\mathrm{Ta}$ ble 1 .

$F$ single crystals* (about one fourth inch in diameter) were sliced perpendicularly to the growth axis, ground flat, and subjected to a four step polishing procedure. The final grit used was AB Gamma Polishing Alumina on $\mathrm{AB}$ Microcloth. $\dagger$ An average roughness of a sample of the polished crystals was obtained with the aid of a profilometer. $\ddagger$ Before being scratched, the crystals were treated in 2-propanol and in distilled

\footnotetext{
* Southwest Scientific Co., Hamilton, Mont.

+ Buehler, Ltd., Evanston, Ill.

* Model AE pilotor with QC amplifier, Micrometrical Mfg. Co., Ann Arbor, Mich.
} 
TABLE 1

EXPERIMENTAL DESIGN FACTORS

\begin{tabular}{lcc}
\hline \multicolumn{1}{c}{ Factor } & Levels & Comments \\
\hline Specimen & 2 & 2 crystals $(3$ replications \\
Slider speed & 2 & 0.025 and $0.076 \mathrm{~cm} / \mathrm{sec}$ \\
Load & 5 & $10,25,50,100$, and $500 \mathrm{gm}$ \\
& $\left(A_{1}\right.$ through $A_{5}$, respec- \\
tively) & $75^{\circ}$ cone, $0.018 \mathrm{~cm}$ radius \\
Slider design & $5 \quad$ & $75^{\circ}$ cone, $0.064 \mathrm{~cm}$ radius \\
& $104^{\circ}$ cone, $0.005-0.008 \mathrm{~cm}$ \\
& radius \\
& $123^{\circ}$ cone, $0.005-0.008 \mathrm{~cm}$ \\
& radius \\
& $143^{\circ}$ cone, $0.005-0.008 \mathrm{~cm}$ \\
& radius \\
& $\left(B_{1}\right.$ through $B_{5}$, respec- \\
& tively) \\
\hline
\end{tabular}

water, and placed in a vacuum desiccator for 30 minutes $(29 \mathrm{~mm} \mathrm{Hg})$. All crystals then were stored in the desiccator at atmospheric pressure until use. Comparison of the natural apatite in powdered form with a synthetic $F^{*}$ was made by means of infrared spectroscopy (IRS) $\dagger$ and X-ray diffraction. $\ddagger$

The apparatus used in this investigation to scratch the surface of a specimen and measure the friction force $\S$ consisted of mechanisms that can be categorized as follows: surface grinder, loading jig, friction transducer, diamond sliders, and sample holder.

A precision surface grinder|l that was modified and tested in previous friction and wear studies ${ }^{11}$ was used to provide a horizontal, linear motion to a specimen mounted on the grinding table. The hydraulic movement afforded a smooth and vibration-free motion at the speeds investigated (Table 1).

The loading jig might be described most simply as a counterbalanced, mechanical parallelogram with oil-impregnated bronze pin-bearings to provide a frictionless vertical motion. The end of the jig directly below the center of the loading plate was tapped to accept the friction transducer.

* X-13283 fluorapatite, General Electric Co., Cleveland, Ohio.

$\dagger$ Model 337 grating infrared spectrophotometer, Perkin-Elmer Corp., Norwalk, Conn.

I Vertical diffractometer, Philips Electronic Instruments, Mt. Vernon, NY.

$\$$ The measurement of friction force will be reported in a later paper.

il Grand Rapids 250, Gallmeyer and Livingston Co., Grand Rapids, Mich.
The lower end of the friction transducer was machined to hold the shait of the diamond slider by means of a set screw. The loading jig, transducer, and diamond slider are shown assembled in Figure 1.

Industrial grade diamonds of five different geometries (Table 1) were designed and prepared\# for use as sliders. The diamonds were mounted on steel shafts and given a gem polish by the manufacturer. Crystallographic orientation of the diamonds was not specified. Before use, the diamonds were given a surface treatment similar to that received by the apatite crystals.

The specimen holder, for tests in a dry environment, was machined from aluminum with a center hole capable of accommodating a single crystal mounted in plastic. Care was taken to mount the surface of the specimen parallel to the grinding table.

To obtain an accurate measurement of speed, a traveling microscope 1 was used to measure the length of the wear tracks. The time of each run was recorded from a stopwatch to the nearest 0.1 second.

The average track width of the wear scars was measured from photographs developed from $4 \times 5$ inch negatives** exposed at an appropriate objective lens magnification $(50 \times$ to $500 \times)$ on a metallograph. $\dagger \dagger$ The metallograph was calibrated to obtain the true magnification of the negatives.

The values of track depth and area were calculated from the corresponding values of track width and slider geometry (in metric units) with the aid of a computer program. The area computed was based on the assumption that only the front half of the slider contributed to the sliding process.

\section{Results}

Comparison of the natural apatite with the synthetic product by means of IRS and $X$-ray diffraction showed only slight differences in parameters. In the IRS analysis, the $v_{3}^{\prime}$ (P-O stretch of ionic $\mathrm{PO}_{4}^{-3}$ ) peak at $1,000 \mathrm{~cm}^{-1}$ and the $\boldsymbol{v}_{4}^{\prime}$ (P-O bending) peak at $560 \mathrm{~cm}^{-1}$ were missing

\footnotetext{
\# Wheel Trueing Tool Company, Detroit, Mich.

I Gaertner Scientific Corp., Chicago, II.

* Panatomic-X Film, Eastman Kodak Co., Rochester, NY.

怙 Aristophot, Ernst Leitz, Wetzlar, Ger.
} 


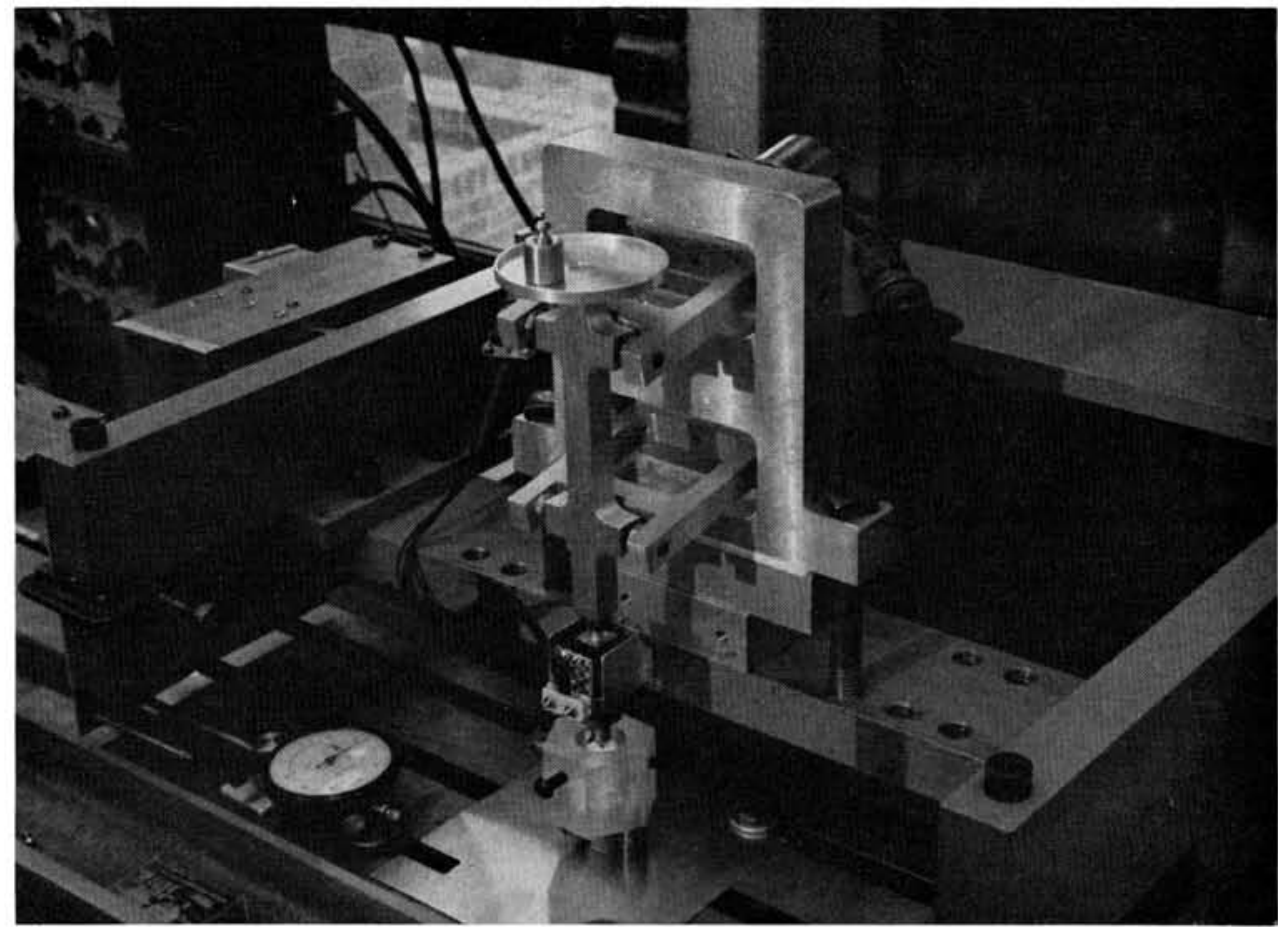

FIG 1.-Assembled loading jig, transducer, and diamond slider.

with the natural apatite. In the X-ray analysis, slight shifts in some $D$-values ${ }^{12}$ were found for the natural $F$ (Table 2).

An average surface roughness of 0.020 micrometers $(\mu \mathrm{m})(\mathrm{rms})$ with a standard deviation of $0.007 \mu \mathrm{m}$ was found for a sample of five crystals traced in two mutually perpendicular directions. No significant directional effect caused by polishing was observed.

The effect of specimen on track width was examined at two levels (two crystals) for five slider designs and five loads with three replications per cell. Unless otherwise indicated, the factorial designs ana- lyzed have a slider speed of $0.025 \mathrm{~cm} / \mathrm{sec}$ and six replications per cell. The null hypothesis $\left(H_{o}\right)$ that there were no differences between the effects at two levels of the specimen was evaluated for the measured variable track width.

The main effect of crystals was not significant $\left(F=0.16<F_{(1,60)}=4.00\right)$ at the 0.05 level. $^{13}$ First order and second order interactions were not significant. There were no differences between the two levels of the specimen, and consequently, the data from three replications on each of two crystals was combined and considered as six replications for the analysis of the

TABLE 2

COMParison OF POWDER-Diffraction (D) VAlues

\begin{tabular}{|c|c|c|c|c|c|}
\hline \multicolumn{2}{|c|}{ NBS Standard ${ }^{12}$} & \multicolumn{2}{|c|}{ Synthetic Fluorapatite } & \multicolumn{2}{|c|}{ Natural Fluorapatite } \\
\hline D-Value & $I / I_{0}{ }^{*}$ & $D$-Value & $I / I_{\theta}$ & D-Value & $I / I_{0}$ \\
\hline 3.442 & 40 & 3.440 & 22 & 3.440 & 47 \\
\hline 2.800 & 100 & 2.801 & 100 & 2.805 & 100 \\
\hline 2.772 & 55 & & $\ldots$ & 2.780 & 65 \\
\hline 2.702 & 60 & 2.702 & 69 & 2.706 & 67 \\
\hline 2.624 & 30 & 2.625 & 23 & 2.629 & 29 \\
\hline 1.837 & 30 & 1.838 & 25 & 1.838 & 39 \\
\hline
\end{tabular}

* $I / I 0$, relative peak intensity where maximum peak intensity equals $I_{0}$ equals 100 . 
load and slider design factors. The coefficient of variation for the data taken before it was combined was $12 \%$.

The effect of specimen on track depth and area was examined. The main effect of crystals on track depth was not significant $\left(F=1.24<F_{(1,60)}=4.00\right)$ at the 0.05 level. The main effect of crystals on area also was not significant $(F=0.02<$ $\left.F_{(1,60)}=4.00\right)$ at the 0.05 level. The coefficients of variation for these data were 16 and $29 \%$, respectively. In each instance first order and second order interactions were not significant.

The effect of slider speed on track width was examined at two levels $(0.025$ and 0.076 $\mathrm{cm} / \mathrm{sec}$ ) for five slider designs at a $500 \mathrm{gm}$ load. The main effect of speed was significant $\left(F=7.91>F_{(1,40)}=7.31\right)$ at the 0.01 level. In general, the lower speed resulted in a larger track width for the two speeds studied. The first order interaction was significant $(P<0.025)$, which indicated that speed and slider design were not independent. The coefficient of variation for this data was $6.1 \%$.

To rank the speeds with respect to constant slider design, Duncan's New Multiple Range Test ${ }^{10}$ was used as shown in Table 3. The speeds were significantly different $(P<0.05)$ only for slider designs $B_{3}$ and $B_{4}$ for the track width variable.

The effect of slider speed on track depth and area was examined as described previously. The main effect of speed on track depth was significant $\left(F=13.8>F_{(1,40)}\right.$ $=12.6$ ) at the 0.001 level. The lower speed resulted in a larger track depth. The main effect of speed on area also was significant $\left(F=14.3>F_{(1,40)}=12.6\right)$ at the 0.001 level. The lower speed resulted in a larger area. The coefficients of variation for these data were 12 and $22 \%$, respectively. In each instance the first order interaction

TABLE 3

Results of Duncan's New Multiple Range TEST FOR SLIDER SPEED DIFFERENCES

\begin{tabular}{lcc}
\hline $\begin{array}{c}\text { Slider } \\
\text { Design }\end{array}$ & $\begin{array}{c}\text { Speed } \\
(\mathrm{cm} / \mathrm{sec})\end{array}$ & $\begin{array}{c}\text { Mean } \\
(\mu \mathrm{m})\end{array}$ \\
\hline$B_{1}$ & $0.025-0.076$ & $49.3-54.7^{*}$ \\
$B_{2}$ & $0.025-0.076$ & $56.4-59.6^{*}$ \\
$B_{3}$ & $0.076-0.025$ & $83.6-107.0$ \\
$B_{3}$ & $0.076-0.025$ & $90.0-106.0$ \\
$B_{5}$ & $0.076-0.025$ & $75.5-86.5^{*}$ \\
\hline Note: Dependent variable, track width. \\
* No significant difference at the 95\% level.
\end{tabular}

between speed and slider design was significant.

The speeds were ranked with respect to constant slider design for the variables track depth and area as described for track width. In each instance, the speeds were significantly different $(P<0.05)$ only for slider designs $B_{3}$ and $B_{4}$. Typical values of track depth and area under these conditions were $22 \mu \mathrm{m}$ and $100 \times 10^{-6} \mathrm{~cm}^{2}$, respectively.

The effect of load on track width was examined at five levels ( $A_{1}$ through $A_{5}$ ) for five slider designs. In conjunction with this, the critical track width $\dagger$ was calculated for each slider design (Table 4). The $500 \mathrm{gm}$ load represented a different plowing situation from the other loads because the mean track widths for slider designs $B_{3}$ through $B_{5}$ exceeded the corresponding critical track widths of the $500 \mathrm{gm}$ load. Therefore, values for the $500 \mathrm{gm}$ load were treated separately from the other values in the statistical analysis of the data.

The main effect of load on track width was significant $\left(F=186>F_{(3,60)}=6.17\right)$ at the 0.001 level. In general, lower loads resulted in lower values of track width over the range studied, including the 500 $\mathrm{gm}$ load. The first order interaction also was significant at the 0.001 level, which indicated that load and slider design were not independent. The coefficient of variation for this data was $8.1 \%$.

The loads were ranked with respect to constant slider design as shown in Table 5. The values for the $500 \mathrm{gm}$ load are included for comparison, but were not ranked statistically. With several exceptions, the loads were significantly different $(P>0.05)$ within a given slider design. Log-log plots of mean track width vs load were straight lines for the designs studied, although the values for the $500 \mathrm{gm}$ load were larger than would have been anticipated by this relationship for slider designs $B_{3}$ through $B_{5}$. Log-log plots of mean track width vs load for slider designs $B_{1}$ and $B_{4}$ are shown in Figure 2. The location of the critical track width of slider design $B_{4}$ corresponded to a critical load of about $250 \mathrm{gm}$. The slopes of these curves for designs $B_{1}$ and

t Critical track width is defined as that width below which only the hemispherical part of a slider contributes to sliding, and above which both the hemispherical and conicial parts of a slider contribute to sliding. 
TABLE 4 Critical Track Widths

\begin{tabular}{cc}
\hline \hline Slider Design & Critical Track Width \\
\hline$B_{1}$ & 282.0 \\
$B_{2}$ & $1,010.0$ \\
$B_{3}$ & 78.3 \\
$B_{4}$ & 48.5 \\
$B_{5}$ & 40.4 \\
\hline
\end{tabular}

$B_{4}$ were 0.445 and 0.640 , respectively. The values of track width for the 50 and 100 gm loads were reversed in order for design $B$.

The main effect of load on track depth was significant $\left(F=420>F_{(3,60)}=6.17\right)$ at the 0.001 level. In general, higher loads resulted in higher values of track depth over the range studied, including the 500 gm load. With two exceptions, the mean
TABLE 5

Results of Duncan's New Multiple RaNGe TEST FOR LOAD DIFFERENCES

\begin{tabular}{cccccc}
\hline \multirow{2}{*}{$\begin{array}{c}\text { Slider } \\
\text { Design }\end{array}$} & \multicolumn{5}{c}{ Ranking of Means $(\mu \mathrm{m})$} \\
\cline { 2 - 6 } & $A_{1}$ & $A_{2}$ & $A_{3}$ & $A_{1}$ & $A_{5}$ \\
\hline$B_{1}$ & 8.85 & 16.9 & 19.2 & 24.5 & 49.3 \\
$B_{2}$ & 13.6 & 22.0 & 45.0 & 34.6 & 56.4 \\
$B_{3}$ & $\mathbf{8 . 1 8}$ & 10.1 & 17.2 & 33.8 & 107 \\
$B_{4}$ & 6.58 & 11.7 & 20.0 & 28.4 & 106 \\
$B_{5}$ & $\underline{7.16}$ & 9.23 & 22.8 & 28.0 & 86.5 \\
\hline
\end{tabular}

Note: Dependent variable, track width. Underscore indicates no significant difference at the $95 \%$ level.

track depth values were 5 to 1,000 times the mean surface roughness value. The mean effect of load on area also was significant $\left(F=89.9>F_{(3,60)}=6.17\right)$ at the 0.001 level. Higher loads resulted in higher values of area over the range of loads studied. The coefficients of variation for

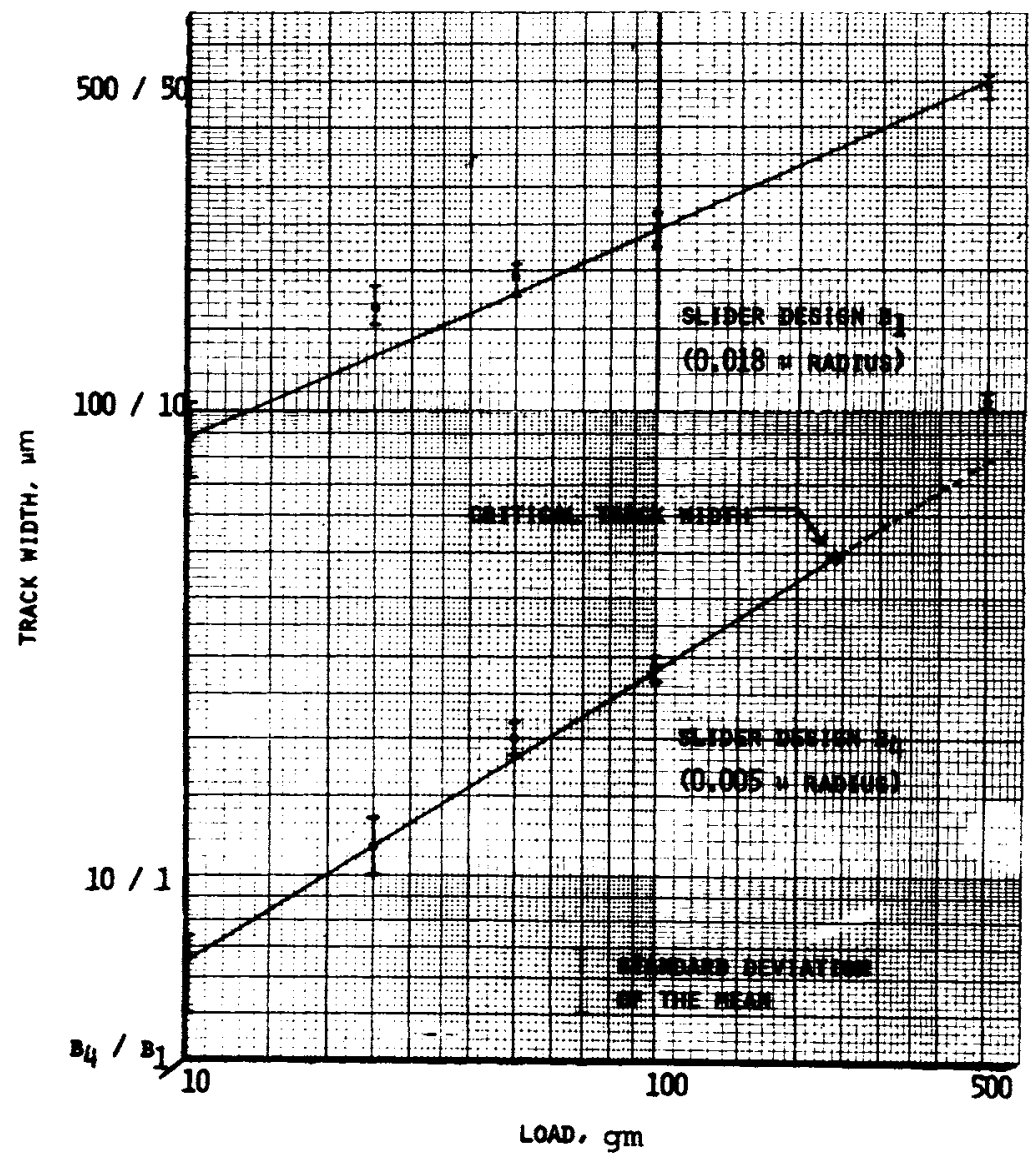

Fig 2.-Relationship between track width and load for two slider designs $(\mu=\mu \mathrm{m})$. 
these data were 11 and $19 \%$, respectively. In each instance the first order interaction between load and slider design was significant at the 0.001 level.

The loads were ranked with respect to constant slider design for the variables track depth and area (Tables 6, 7). The values for the $500 \mathrm{gm}$ load are included for comparison, but were not ranked statistically. In both instances, values for the $500 \mathrm{gm}$ load were an order of magnitude larger than values for the $100 \mathrm{gm}$ load for designs $B_{3}$ through $B_{5}$.

The effect of slider design on track width was examined at five levels ( $B_{1}$ through $B_{5}$ ) for five loads. The main effect of slider design was significant $(F=44.8>$ $\left.F_{(4,60)}=5.31\right)$ at the 0.001 level. Slider designs with smaller radiuses resulted in lower values of track width with the designs studied. The coefficients of variation for this and the following data are identical to those reported for load.

The designs were ranked with respect to constant load, as shown in Table 8 . The values for the $500 \mathrm{gm}$ load are included for comparison and were ranked based on the data presented in Table 3. There appeared to be no significant difference $(P<$ 0.05 ) among the means of slider designs $B_{3}$ through $B_{5}$, with the exception of the $500 \mathrm{gm}$ load values. At loads below 100 $\mathrm{gm}$, these designs resulted in the lowest track widths. At the $500 \mathrm{gm}$ load, however, those slider designs with large radiuses $\left(B_{1}\right.$ and $\left.B_{2}\right)$ resulted in low values of track width and were not significantly different $(P<0.05)$ from each other.

The main effect of slider design on track depth was significant $\left(F=116>F_{(4,60)}=\right.$ 5.31 ) at the 0.001 level. The main effect of slider design on area also was significant $\left(F=27.5>F_{(4,60)}=5.31\right)$ at the 0.001

TABLE 6

Results of Duncan's New Multiple Range TEST FOR LOAD DIFFERENCES

\begin{tabular}{cccccc}
\hline \hline \multirow{2}{*}{$\begin{array}{c}\text { Slider } \\
\text { Design }\end{array}$} & \multicolumn{5}{c}{ Ranking of Means $(\mu \mathrm{m})$} \\
\cline { 2 - 6 } & $\boldsymbol{A}_{1}$ & $\boldsymbol{A}_{2}$ & $\boldsymbol{A}_{3}$ & $\boldsymbol{A}_{4}$ & $\boldsymbol{A}_{5}$ \\
\hline $\boldsymbol{B}_{1}$ & 0.06 & $\mathbf{0 . 2 2}$ & $\underline{0.26}$ & 0.43 & 1.7 \\
$B_{2}$ & $\underline{0.04}$ & $\overline{0.10}$ & $\overline{0.41}$ & 0.25 & 0.64 \\
$B_{3}$ & $\underline{0.16}$ & 0.20 & 0.58 & 2.3 & 25 \\
$B_{4}$ & 0.11 & 0.34 & 1.0 & 2.1 & 22 \\
$B_{5}$ & $\underline{0.12}$ & 0.17 & 1.0 & 1.5 & 11 \\
\hline
\end{tabular}

Note: Dependent variable, track depth. Underscore indicates no significant difference at the $95 \%$ level.
TABLE 7

Results of Duncan's New Multiple Range TEST FOR LOAD DIFFERENCES

\begin{tabular}{cccccc}
\hline \hline \multirow{2}{*}{$\begin{array}{c}\text { Slider } \\
\text { Design }\end{array}$} & \multicolumn{5}{c}{ Ranking of Means $\left(10^{-0} \mathrm{~cm}^{2}\right)$} \\
\cline { 2 - 6 } & $A_{1}$ & $A_{2}$ & $A_{3}$ & $A_{4}$ & $A_{5}$ \\
\hline$B_{1}$ & 0.33 & 1.2 & 1.5 & 2.4 & 9.7 \\
$B_{2}$ & 0.74 & $\overline{2.1}$ & $\overline{\gamma .1}$ & 5.0 & 13 \\
$B_{3}$ & 0.31 & 0.39 & 1.2 & 4.6 & 120 \\
$B_{4}$ & 0.17 & 0.55 & 1.6 & 3.4 & 160 \\
$B_{5}$ & 0.24 & $\mathbf{0 . 3 4}$ & 2.1 & $\mathbf{3 . 0}$ & 100 \\
\hline
\end{tabular}

Note: Dependent variable, area. Underscore indicates no significant difference at the $95 \%$ level.

level. Ranking of slider designs with respect to constant load for the variables track depth and area is shown in Tables 9 and 10, respectively. Significant differences among means could be observed only for the higher loads in each instance. In contrast with track width values, the higher track depth values were observed with slider designs $B_{3}$ through $B_{5}$. Higher area values were observed with slider designs $B_{3}$ through $B_{5}$ for the $500 \mathrm{gm}$ load.

\section{Discussion}

The discrepancies noted during comparison of the natural apatite with the synthetic product indicate the presence of impurities in the natural crystal. Although it would be improper to assume that single crystals of natural and synthetic apatite would yield the same data under similar experimental conditions, it is probable that the trends observed would be similar. It is not known whether the behavior of $F$ single crystals is indicative of the behavior of enamel under similar conditions.

The purpose of the polishing and surface treatment procedures was to standardize the crystals. However, different levels of surface roughness 4 and different surface treatments ${ }^{6}$ might be expected to produce different results. Buckley, ${ }^{6}$ for example, has shown that the number and depth of surface and subsurface cleavage cracks for single crystals of calcium fluoride were sensitive to the environmental species present as well as to the load.

A basic assumption underlying the use of analysis of variance and multiple comparisons is that all sample means have statistically equal variances. ${ }^{14}$ When this assumption is not met, the power of these statistical tools is lessened, and true differences among means may not bo observed. 
TABLE 8

Results of Duncan's New Multiple Range Test FOR SLIDER DESIGN DIFFERENCES

\begin{tabular}{llccccc}
\hline \hline Load & & \multicolumn{5}{c}{ Ranking $(\mu \mathrm{m})$} \\
\hline$A_{1}$ & Slider design & $B_{4}$ & $B_{5}$ & $B_{3}$ & $B_{1}$ & $B_{3}$ \\
& Mean & 6.58 & 7.16 & 8.18 & 8.85 & 13.6 \\
\cline { 2 - 7 }$A_{2}$ & Slider design & $B_{5}$ & $B_{3}$ & $B_{4}$ & $B_{1}$ & $B_{2}$ \\
& Mean & 9.23 & 10.1 & 11.7 & 16.9 & 22.0 \\
$A_{3}$ & Slider design & $B_{3}$ & $B_{1}$ & $B_{4}$ & $B_{5}$ & $B_{2}$ \\
& Mean & 17.2 & 19.2 & 20.0 & 22.8 & 45.0 \\
$A_{5}$ & Slider design & $B_{1}$ & $B_{5}$ & $B_{4}$ & $B_{3}$ & $B_{2}$ \\
& Mean & 24.5 & 28.0 & 28.4 & 33.8 & 34.6 \\
$A_{5}$ & Slider design & $B_{1}$ & $B_{3}$ & $B_{5}$ & $-B_{4}$ & $B_{3}$ \\
& Mean & 49.3 & 56.4 & 86.5 & $\underline{106}$ & 107 \\
\hline
\end{tabular}

Note: Dependent variable, track width. Underscore indicates no significant difference at the $95 \%$ level.

The assumption of equal variances was violated in several instances where values ranged over several orders of magnitude. These statistical tools represent a convenient means of data analysis and impose a conservative restriction on interpretation of the results.

As stated earlier, it was assumed that the effect of crystallographic direction on failure properties was of less importance than other factors. The low $F$ values found in comparisons of two crystals with three replications (of arbitrary sliding direction) imply that this assumption was valid for the variables examined. Yet, anisotropic effects have been observed by several investigators for a number of crystals, ${ }^{5,7,8}$ including the hexagonal crystal sapphire. ${ }^{15}$

A strain rate effect on the variables track width, track depth, and area was observed under conditions of a $500 \mathrm{gm}$ load for slider designs $B_{3}$ and $B_{4}$. Under these con- ditions, the wear scar was influenced by the conical and hemispherical sections of the sliders, and much deeper penetration occurred than with other designs. For designs $B_{3}$ and $B_{4}$, the observed track widths were twice that of the respective critical track widths. No strain rate effect was observed for designs and loads in which the observed track widths were less than the critical track widths. Buckley ${ }^{6}$ observed that the amount of track deformation of calcium fluoride decreases with increased sliding speed.

All three variables were sensitive to load and slider design. The track width was related to the load by an equation of the form $L=\psi w^{n}$, where $L$ and $w$ are the load and width, respectively, for slider designs $B_{1}$ and $B_{4}$. Such a relationship has been discussed by Steijn ${ }^{4}$ for single crystals of $\mathrm{NaCl}, \mathrm{LiF}$, and $\mathrm{MgO}$. Values of $n$ reported for these materials were $2.27,2.33$,

TABLE 9

Results of Duncan's New Multiple Range Test FOR SLIDER DESIGN DIfFERENCES

\begin{tabular}{|c|c|c|c|c|c|c|}
\hline \multicolumn{3}{|l|}{ Load } & \multicolumn{3}{|c|}{ Ranking $(\mu \mathrm{m})$} & \multirow[b]{2}{*}{$\begin{array}{c}B_{3} \\
0.16\end{array}$} \\
\hline$A_{1}$ & $\begin{array}{l}\text { Slider design } \\
\text { Mean }\end{array}$ & $\begin{array}{c}B_{2} \\
0.04 \\
\end{array}$ & $\begin{array}{c}B_{1} \\
0.06 \\
\end{array}$ & $\begin{array}{c}B_{4} \\
0.11 \\
\end{array}$ & $\begin{array}{c}B_{5} \\
0.12 \\
\end{array}$ & \\
\hline$A_{2}$ & $\begin{array}{l}\text { Slider design } \\
\text { Mean }\end{array}$ & $\begin{array}{c}B_{2} \\
0.10 \\
\end{array}$ & $\begin{array}{c}B_{5} \\
0.17 \\
\end{array}$ & $\begin{array}{c}B_{3} \\
0.20 \\
\end{array}$ & $\begin{array}{c}B_{1} \\
0.22 \\
\end{array}$ & $\begin{array}{c}B_{4} \\
0.34\end{array}$ \\
\hline$A_{3}$ & $\begin{array}{l}\text { Slider design } \\
\text { Mean }\end{array}$ & $\begin{array}{c}B_{1} \\
0.26 \\
\end{array}$ & $\begin{array}{l}B_{2} \\
0.41 \\
\end{array}$ & $\begin{array}{c}B_{3} \\
0.58\end{array}$ & $\begin{array}{r}B_{4} \\
1.0 \\
\end{array}$ & $\begin{array}{c}B_{5} \\
1.0\end{array}$ \\
\hline$A_{4}$ & $\begin{array}{l}\text { Slider design } \\
\text { Mean }\end{array}$ & $\begin{array}{c}B_{2} \\
0.25 \\
\end{array}$ & $\begin{array}{c}B_{1} \\
0.43 \\
\end{array}$ & $\begin{array}{c}B_{5} \\
1.5\end{array}$ & $\begin{array}{r}B_{4} \\
2.1 \\
\end{array}$ & $\begin{array}{r}B_{3} \\
2.3 \\
\end{array}$ \\
\hline$A_{5}$ & $\begin{array}{l}\text { Slider design } \\
\text { Mean }\end{array}$ & $\begin{array}{c}B_{2} \\
0.64 \\
\end{array}$ & $\begin{array}{r}B_{1} \\
1.7 \\
\end{array}$ & $11^{B_{5}}$ & $22^{B_{4}}$ & $25^{B_{3}}$ \\
\hline
\end{tabular}

Note: Dependent variable, track depth. Underscore indicates no significant difference at the $95 \%$ level. 
TABLE 10

Results of Duncan's New Multiple Range Test FOR SLIDER DESIGN Differences

\begin{tabular}{llccccc}
\hline \hline Load & & \multicolumn{5}{c}{ Ranking $\left(10^{-8} \mathrm{~cm}^{2}\right)$} \\
\hline$A_{1}$ & Slider design & $B_{4}$ & $B_{5}$ & $B_{3}$ & $B_{1}$ & $B_{2}$ \\
& Mean & 0.17 & 0.24 & 0.31 & 0.33 & 0.74 \\
\cline { 2 - 7 }$A_{2}$ & Slider design & $B_{5}$ & $B_{3}$ & $B_{5}$ & $B_{1}$ & $B_{2}$ \\
& Mean & 0.34 & 0.39 & 0.55 & 1.2 & 2.1 \\
\cline { 2 - 7 }$A_{3}$ & Slider design & $B_{3}$ & $B_{1}$ & $B_{4}$ & $B_{5}$ & $B_{2}$ \\
& Mean & 1.2 & 1.5 & 1.6 & 2.1 & 8.1 \\
$A_{4}$ & Slider design & $B_{1}$ & $B_{5}$ & $B_{4}$ & $B_{3}$ & $B_{2}$ \\
& Mean & 2.4 & 3.0 & 3.4 & $\frac{4.6}{B_{5}}$ & 5.0 \\
\cline { 2 - 7 } & Slider design & $B_{1}$ & $B_{2}$ & $B_{5}$ & 130 & 160 \\
\hline & Mean & 9.7 & 13 & 100 & 120 & $B_{4}$ \\
\hline
\end{tabular}

Note: Dependent variable, area. Underscore indicates no significant difference at the 95\% level.

and 2.45 , respectively. The values of $n$ for designs $B_{1}$ and $B_{4}$ on single crystals of $F$ were 2.25 and 1.56 , respectively, as calculated from the reciprocal of the slopes in Figure 2. Although not shown in Figure 2, the data for slider designs $B_{3}$ and $B_{5}$ were approximated well by the relationship for slider design $B_{4}$. Such curves may be characteristic of the hemispherical contribution of the sliders up to a point determined by the critical track width and apical angle of the design. A slider design with a sharp apical angle (eg, $B_{4}$ ) can be expected to deviate from this linear log-log relationship more dramatically than one with a blunter angle $\left(\mathrm{eg}, B_{5}\right)$ at loads above their critical load for designs of similar radiuses.

Penetration caused by sliding was relatively low below the critical track width for all slider designs, but above this value, there was a considerable increase in penetration for the sharper angles. However, below the critical track width, those sliders with smaller radiuses resulted in larger penetration at a given load. These results are similar to those observed by Bowden and $\mathrm{Brookes}^{8}$ in their study of $\mathrm{MgO}$ single crystals, and by Steijn ${ }^{4}$ in his study of copper.

Values for track depth and area were not as effective as track width in ranking the data because of the propagation of error in their respective calculations. In spite of this, both were valuable in explanations of the observed behavior, and should not be discarded. Values obtained for slider design $B_{2}$ were questionable in several instances, and this was thought to be the result of the effect of first order asperities on the large diameter slider.

\section{Conclusions}

A quantitative method for characterizing the surface failure of nonmetallic single crystals under sliding was evaluated by an investigation of the wear of natural fluorapatite single crystals. The method consisted of sliding a diamond of specific design on the basal surface of natural fiuorapatite single crystal in a dry environment, and required apparatus characterized as follows: surface grinder, loading jig, friction transducer, diamond slider, and sample holder.

The variables track width, track depth, and area were effective in ranking data obtained under varying conditions of slider speed, load, and slider design. Although less accurate because of propagation of error, the variables track depth and area were valuable in explaining observed behavior.

A strain rate effect was observed at a $500 \mathrm{gm}$ load for slider designs with small radiuses and sharp apical angles. In these designs a lower sliding speed resulted in increased surface damage.

Track width was related to the load by a linear log-log relationship under those conditions of load and design where the critical track width had not been exceeded. Above this critical value, track width was related to the sharpness of the apical angle of the diamond.

Penetration was favored by slider designs of small radiuses, and for the same slider, by higher loads. 


\section{References}

1. GRABENSTETTER, R.J.; BROGE, R.W.; JACKSON, F.L.; and Radike, A.W.: The Measurement of the Abrasion of Human Teeth by Dentifrice Abrasion: A Test Utilizing Radioactive Teeth, $J$ Dent Res 37:1060-1068, 1958.

2. STookey, G.K., and Muhler, J.C.: Laboratory Studies Concerning the Enamel and Dentin Abrasion Properties of Common Dentifrice Polishing Agents, J Dent Res 47:524-532, 1968.

3. WRIGHT, K.H.R., and STEvenSON, J.I.: The Measurement and Interpretation of Dentifrice Abrasiveness, J Soc Cos Chem 18:387-407, 1967.

4. SteIJN, R.P.: Friction and Wear of Single Crystals, Wear 7:48-66, 1964.

5. SteiJn, R.P.: Friction and Wear of Nonmetallic Solid Materials, Technical Report AFML-TR-67-91, 1967.

6. BUCKLEY, D.H.: Effect of Surface Active Media on Friction, Deformation and Fracture of Calcium Fluoride, NASA TN D-5580, 1969.

7. Bowden, F.P.; Brookes, C.A.; and HaNWELL, A.E.: Anisotrophy of Friction in Crystals, Nature 203(4930):27-29, 1964.
8. Bowden, F.P., and Brookes, C.A.: Frictional Anisotrophy in Non-Metallic Crystals, Proc Roy Soc (London) A295:244258, 1966.

9. Dalby, John: Analysis of Variance, Statistical Research Laboratory, Ann Arbor: University of Michigan, 1968.

10. Duncan, D.B.: Multiple Range and Multiple F-test, Biometrics 11:1-42, 1955.

11. Tillitson, E.W.; Craig, R.G.; Koran, A.; and Peyton, F.A.: Friction and Wear of Dental Materials, IADR Annual Meeting, Houston, Texas, March 1969, Paper No. 358, DMG Microfilm.

12. Swanson, S.E.; Morris, M.C.; Evans, E.H.; and ULMER, Linda: Standard X-ray Diffraction Powder Patterns, Washington, DC: National Bureau of Standards, Mono 25-3, 1959.

13. Dixon, W.J., and MASSEY, F.J., JR.: Introduction to Statistical Analysis, New York: McGraw-Hill, 1957, pp 388-403.

14. Scheffe, Henry: The Analysis of Variance, New York: Wiley, 1959.

15. BUCKLEY, D.H.: Friction Characteristics in Vacuum of Single and Polycrystalline Aluminum Oxide in Contact With Themselves and With Various Metals, ASLETrans 10:134-145, 1967. 